\title{
OPTIMIZED BAKING OF THE DIII-D VESSEL
}

\author{
by \\ P.M. ANDERSON and A.G. KELLMAN
}

This is a preprint of a paper to be presented at the 18th IEEE/NPSS Symposium on Fusion Engineering, October 25-29, 1999, in Albuquerque, New Mexico, and to be published in the Proceedings.

\author{
Work supported by \\ the U.S. Department of Energy \\ under Contract No. DE-AC03-99ER54463
}




\section{DISCLAIMER}

This report was prepared as an account of work sponsored by an agency of the United States Government. Neither the United States Government nor any agency thereof, nor any of their employees, make any warranty, express or implied, or assumes any legal liability or responsibility for the accuracy, completeness, or usefulness of any information, apparatus, product, or process disciosed, or represents that its use would not infringe privately owned rights. Reference herein to any specific commercial product, process, or service by trade name, trademark, manufacturer, or otherwise does not necessarily constitute or imply its endorsement, recommendation, or favoring by the United States Government or any agency thereof. The views and opinions of authors expressed herein do not necessarily state or reflect those of the United States Government or any agency thereof. 


\section{DISCLAIMER}

Portions of this document may be illegible in electronic image products. Images are produced from the best available original document. 


\title{
Optimized Baking of the DIII-D Vessel ${ }^{*}$
}

\author{
P.M. Anderson and A.G. Kellman \\ General Atomics, P.O. Box 85608, San Diego, California 92186-5608
}

\begin{abstract}
The DIII-D tokamak vacuum vessel baking system is used to heat the vessel walls and internal hardware to an average temperature of $350^{\circ} \mathrm{C}$ to allow rapid conditioning of the vacuum surfaces. The system combines inductive heating and a circulating hot air system to provide rapid heating with temperature uniformity required by stress considerations. In recent years, the time to reach $350^{\circ} \mathrm{C}$ had increased from 9 hrs to $14 \mathrm{hrs}$. To understand and remedy this sluggish heating rate, an evaluation of the baking system was recently performed. The evaluation indicated that the mass of additional in-vessel hardware (50\% increase in mass) was primarily responsible. This paper reports on this analysis and the results of the addition of an electric air heater and procedural changes that have been implemented. Preliminary results indicate that the time to $350^{\circ} \mathrm{C}$ has been decreased to 4.5 hours and the temperature uniformity has improved.
\end{abstract}

\section{DIII-D VESSEL BAKING SYSTEM DESCRIPTION}

The DIII-D tokamak vacuum vessel baking system evolved from the inductive heating system used on Doublet III between 1979 and 1984. This system is used to heat the vessel and internal hardware to an average of $350^{\circ} \mathrm{C}$ for outgassing and vessel conditioning purposes in order to prepare it for operation with high temperature tokamak plasmas. Reducing levels of water and oxygen in graphite plasma facing protective tiles lowers radiation loss during operation. Reducing the deuterium background improves density control during plasma operations allowing the lowdensity operation that is required for enhanced plasma performance regimes. Heating graphite to about $350^{\circ} \mathrm{C}$ has been shown to accelerate vessel conditioning significantly. The ability to rapidly heat, hold steady temperature and rapidly cool down, is beneficial to condition the vessel, remove injected trace gasses, or reduce deuterium levels for helium leak checking.

The DIII-D vacuum vessel prior to installation of insulation is shown in Fig. 1. The vessel is one piece with no electrical breaks. High temperature baking of the entire system is necessary to rapidly recover good vacuum conditions after an air vent of the vessel. The construction of $90 \%$ of the vessel is of double wall Inconel sheet with corrugated separators between inner and outer skins. This looks similar to the construction of cardboard box material. The corrugations form 120 poloidal flow passages which are combined into 60 parallel circuits within the vessel walls. Analysis during the design process of the outer mid-plane area of the vessel indicated that the corrugated design would be

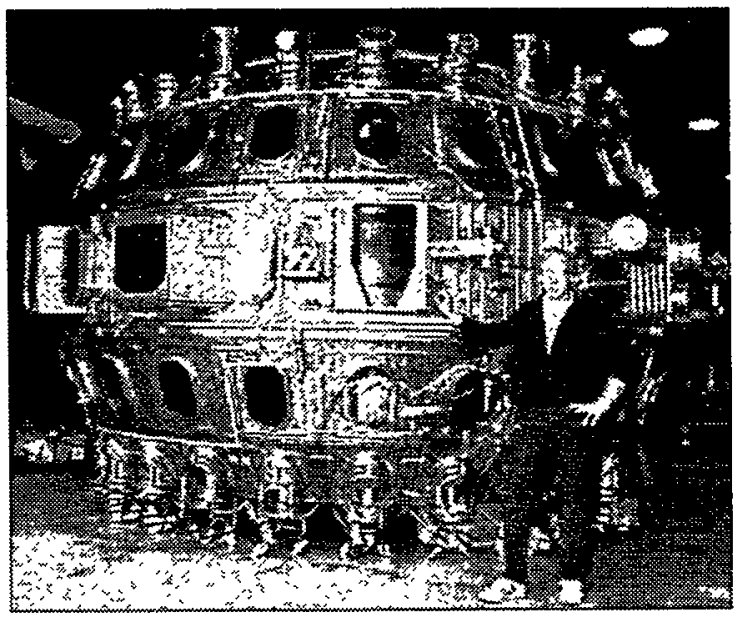

Fig. 1. DIII-D Vessel during preparation for installation.

structurally inadequate when large port areas were cut into the wall. For this reason, the mid-plane section is made from solid $25.4 \mathrm{~mm}$ thick Inconel plate. Figure 1 also shows the heating/cooling tubes attached to ports that extend from the vessel and the ladder like heating/cooling passages welded to the solid mid-plane wall.

The double wall Inconel vessel is heated primarily by inductive eddy currents generated using the 122 turn, water cooled, ohmic heating coil. In order to efficiently couple power to the vessel, a resonant power converter system supplies $21 \mathrm{~Hz}$ power producing approximately $175 \mathrm{KW}$ of heating when operated at $100 \%$ duty cycle. The duty cycle is adjustable from 0 to $100 \%$ which adjusts the time on and off within a $10 \mathrm{~s}$ period. Due to the smaller circumference (lower electrical resistance) of the inner wall as compared to the outer wall, the inductive heating rate is about a factor of 6 higher on the inner wall as compared to the outer wall. The uneven heating rates shown in Fig. 2 [1] creates a temperature and thermal stress imbalance between the inner and outer walls of the vessel. The local heat generation rate is assumed to be inversely proportional to the distance from the vertical centerline of the tokamak and is also related to the local conductivity which varies with material thickness and voids at

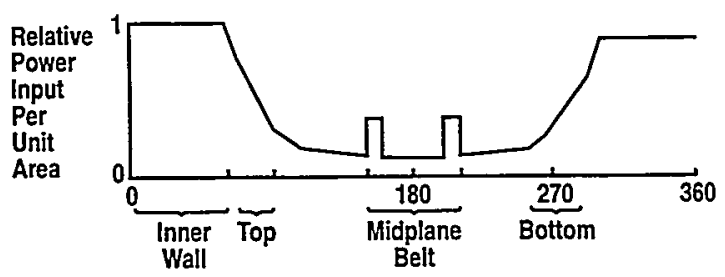

Fig. 2. DIII-D vessel inductive heating rate versus poloidal location.

\footnotetext{
${ }^{*}$ Work supported by U.S. Department of Energy under Contract No. DE-AC03-99ER54463.
} 


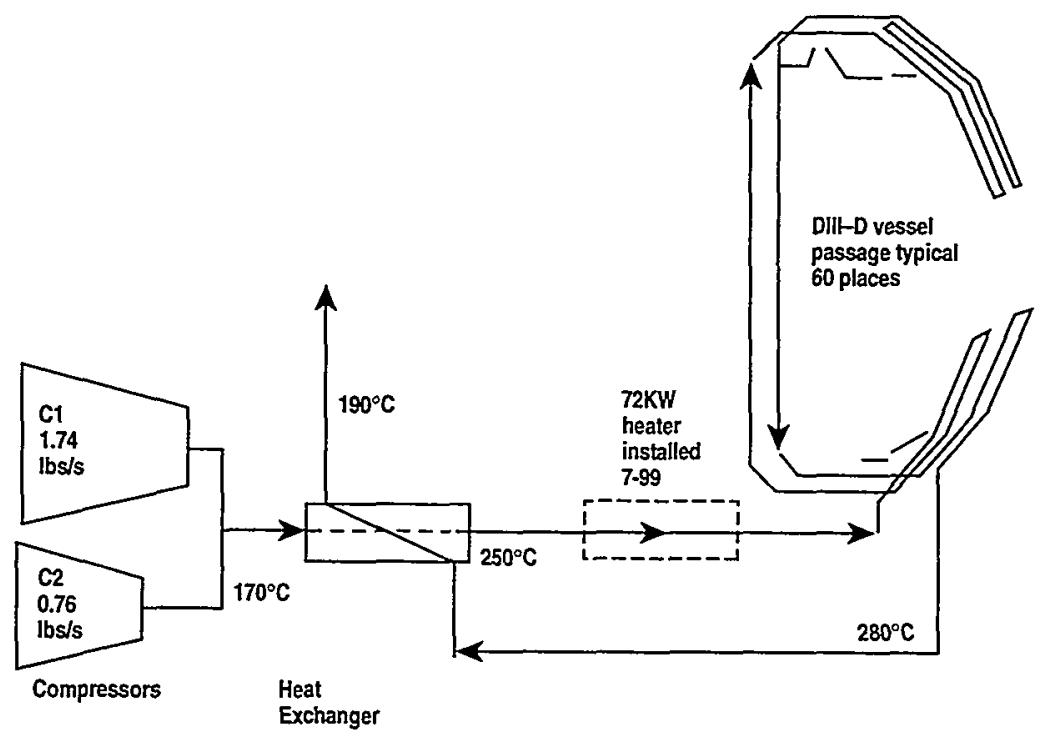

Fig. 3. Simplified schematic of DIII-D baking air flow system.

port locations. These thermal stresses became obvious when the previous Doublet III (DIII) vessel buckled a local area of the floor along a corrugation during inductive baking to about $250^{\circ} \mathrm{C}$. The DIII vessel was of corrugated construction with no forced fluid flow within the corrugations. Although permanently deformed, no leak was created. Learning from our DIII experience, DIII-D utilities forced airflow through the poloidal corrugations to transfer heat from the inner wall to the outer wall to maintain the difference between the average inner wall and average outer wall temperature to less than $100^{\circ} \mathrm{C}$.

All heating and cooling passages in the vessel, ports, invessel divertor panels, mid-plane areas, etc. are connected to a common Air/Water Control System (AWCS). A simplified diagram of this air flow system is shown in Fig. 3. Lines have orifices installed to roughly balance flow rates. For instance, some of the 60-poloidal vessel channels differ by a factor of 3 in flow resistance due to restrictions that occur when fluid flow is directed around port areas. Orifice balancing of these channels distribute fluid flow acceptably. The AWCS is controlled by a Programmable Logic Controller (PLC) which controls $2000 \mathrm{l} / \mathrm{m}$ of water flow (550 GPM) during plasma operation and up to $1.1 \mathrm{Kg} / \mathrm{s}(2.5 \mathrm{lbs} / \mathrm{s})$ of compressed air at $3 \mathrm{~atm}$ ( $45 \mathrm{psi}$ ) for heating and temperature balancing of the vessel during vessel baking to an average vessel temperature of $350^{\circ} \mathrm{C}\left(662^{\circ} \mathrm{F}\right)$. The AWCS incorporates double block valves with interspace drain to separate the water from the high temperature air.

The DIII-D vessel baking system was first used in early 1986. Since that time the thermal mass has increased about $50 \%$ due to added vessel armor tiles, divertor hardware, ICH launchers, diagnostics, etc. and surface area for heat transfer to atmosphere has increased perhaps $10 \%$. Minor flow changes in the AWCS system were made to heat the in-vessel divertor hardware. These changes have occurred gradually and have resulted in a slow increase in the time to an average vessel temperature of $350^{\circ} \mathrm{C}$ from around $9 \mathrm{hrs}$ in 1986 to $14 \mathrm{hrs}$ in 1998.

\section{EVALUATION OF SYSTEM PERFORMANCE}

Figure 4 shows the heat balance versus vessel temperature for the DIII-D baking system as of 12-99. This figure shows $165 \mathrm{~kW}$ of inductive heating independent of vessel temperature. This power is difficult to measure. The resonant power converter system supplies $21 \mathrm{~Hz}$ power producing about $175 \mathrm{~kW}$ of heating. Some loss occurs in the buswork and some heating occurs in the metallic coil cases which surround 4 of the 122 turns of the E-coil. A second source of heat is the compressed air. Atmospheric air compressed to $3 \mathrm{~atm}$ is heated to about $180^{\circ} \mathrm{C}\left(356^{\circ} \mathrm{F}\right)$ and can be supplied to the vessel at about $170^{\circ} \mathrm{C}$ through a $120 \mathrm{~m}$ long pipe system. This hot air is beneficial in heating the vessel at lower temperatures but when the vessel is above $170^{\circ} \mathrm{C}$, the once through air system actually cools the vessel since the outlet temperature is greater than the inlet temperature. When the outlet temperature exceeds the inlet temperature, an outlet air to inlet air heat exchanger with $70 \%$ efficiency is used to recover waste heat and boost inlet air temperature to $250^{\circ} \mathrm{C}$ reducing the cooling effect of the airflow. The thermal loss from the approximately $90 \mathrm{sq} \mathrm{m}$ of $1.26 \mathrm{~cm}$ thick insulation is estimated to be $130 \mathrm{~kW}$ at an average vessel temperature of $350^{\circ} \mathrm{C}$. As shown in Fig. 4, the net heat input is about $240 \mathrm{~kW}$ at $30^{\circ} \mathrm{C}$ declining to $10 \mathrm{~kW}$ at $350^{\circ} \mathrm{C}$ which is quite consistent with the slow rate of rise of vessel temperature, about $4^{\circ} \mathrm{C} / \mathrm{hr}$, which occurred at $350^{\circ} \mathrm{C}$ vessel temperature.

Two areas for improvement were evident from evaluation of baking data. They were:

First, excessive time required to reach $350^{\circ} \mathrm{C}$ vessel average temperature. The staff supports two $8 \mathrm{hr}$ shifts for baking. Since it required $14 \mathrm{hrs}$ to reach $350^{\circ} \mathrm{C}$, only $2 \mathrm{hrs}$ were available for steady state baking at peak temperature. This required more frequent baking than desired. 


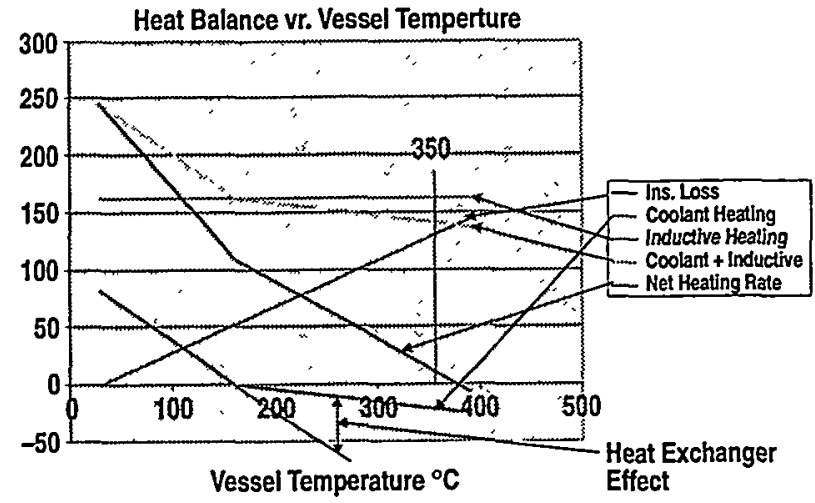

Fig. 4. Heat balance versus temperature for DIII-D baking 12-98.

Second, the inlet air to the vessel was $250^{\circ} \mathrm{C}$ maximum when the vessel average temperature was $350^{\circ} \mathrm{C}$. This cooler air depressed the temperature of portions of the system at air entry locations. This meant that the lower outer areas of the vessel, portions of the in-vessel divertor structure and vessel ports were undesirably cool during the bake. Since graphite tiles are directly attached to the entire inside surface of the vessel and divertors, these tiles remained cooler and probably limited the quality of the vessel conditioning.

\section{CHANGES TO BAKING SYSTEM AND PROCEDURES}

Baking system improvements were implemented in 2 phases over 10 bakes between 12-98 and 7-99. Certain considerations, such as increased inductive heating power or improved vessel insulation, were rejected as impractical.

To reduce the time required to $350^{\circ} \mathrm{C}$, two phase 1 improvements were incorporated as follows:

First, to maximize air temperature delivered from the two air compressors, a $7.5 \mathrm{~cm}$ ( 3 in) back pressure control valve was installed and is now PLC controlled to maintain 2.85 to $3.00 \mathrm{~atm}$ pressure output from the compressors. Prior to this addition, a $15 \mathrm{~cm}$ ( $6 \mathrm{in})$ valve was remotely set by operator command. This valve was nearly shut to develop the required back pressure and the controllability of this valve resulted in reliable operation at 2.5 to $2.8 \mathrm{~atm}$. The compressors trip off at $3.1 \mathrm{~atm}$ and changes in air density due to temperature changes required periodic attention to valve position. This change improved air inlet temperature to the heat exchanger from about $180^{\circ} \mathrm{C}$ to $190^{\circ} \mathrm{C}$.

Second, the baking system was commissioned in $12-85$ and at that time is was clearly demonstrated that both air compressors $(0.35 \mathrm{Kg} / \mathrm{s}$ and $0.75 \mathrm{Kg} / \mathrm{s})$ were necessary to maintain the thermal stress limit of $100^{\circ} \mathrm{C}$ difference between the inner and outer wall average temperatures and this was adopted in the operating procedures. This 1985 testing was done with a bare Inconel vessel. The vessel is now completely covered with graphite tiles directly mounted on the vessel wall. This change has doubled the thermal emissivity of the interior of the vessel which becomes a significant factoronce the system reaches an average temperature of around $300^{\circ} \mathrm{C}$. This change allows operation of the single large compressor to maintain acceptable temperature uniformity. By reducing the mass flow through the vessel, the cooling effect of the airflow is reduced.

The result of these two changes was to reduce the time to reach $350^{\circ} \mathrm{C}$ vessel average from 14 to $8 \mathrm{hrs}$ while increasing the inner to outer wall temperature difference from $66^{\circ} \mathrm{C}$ to $77^{\circ} \mathrm{C}$ at $350^{\circ} \mathrm{C}$.

Phase 2 was implemented to increase air temperature delivered to the vessel in order to improve temperature uniformity. A $72 \mathrm{~kW}$ electric resistance heater was installed after the outlet to inlet air heat exchanger to boost air temperature at the vessel from $250^{\circ} \mathrm{C}$ to $326^{\circ} \mathrm{C}$ while eliminating the cooling effect of the airflow through the vessel corrugations. This traded air heating for inductive heating at steady-state while reducing the time required reaching $350^{\circ} \mathrm{C}$ to $4.5 \mathrm{hrs}$.

\section{THERMAL MODELING OF THE DIII-D BAKING SYSTEM}

In order to better evaluate the performance of the baking system, these Excel models were developed as follows:

Model 1. An overall model to understand the basic relationship of heat inputs and losses as shown in Fig. 4.

Model 2. An empirical model which included compressor heat input, heat exchanger performance, vessel inductive heating, vessel insulation losses, system piping thermal losses, heating from $72 \mathrm{KW}$ in-line air heater, gross effect of radiation heat transfer, etc. These parameters were adjusted using correction factors to match the performance of the system.

Model 3. An empirical model to project port temperatures for future conditions based on fitting port temperature data to determine the relationship of heat from hot air flow, inductive heating, and radiant heating from the vessel inner wall.

Baking data was collected, and system improvements were incorporated, over an eight month period of ten bakes starting in December 1998. These bakes were typically for 8 or $16 \mathrm{hr}$ periods and included 1 and 2 comperssor operation, improvements in compressor pressure output, and a noninductive, compressor only bake resulting in an average vessel temperature of $137^{\circ} \mathrm{C}$ from the compressor heated air. There was some concern from diagnostic personnel that the expected increase in port temperatures could affect the condition of specific diagnostic equipment. Six of about 120 ports were instrumented with thermocouples to measure port flange temperatures.

Model 1, by inputting the mass, specific heat and heat inputs and losses, was useful in understanding the transient heating rate and time to $350^{\circ} \mathrm{C}$ average for various conditions.

Model 2 was more complex than model 1 and progressively linked the air flow from compressors to exhaust 
accounting for heat inputs and losses along the way for steady state conditions only. This model was tuned to match both the non-inductive bake conditions and the reference $350^{\circ} \mathrm{C}$ bake. This model was used to predict three steady-state operating points for evaluating port temperature coefficients for input to model 3. The predictive accuracy of this model wasn't as good as expected for predicting average vessel temperature for partial inductive power or off normal air inlet temperatures. The model projects that the $72 \mathrm{KW}$ air heater when used with the heat produced by the air compressor should be able to bake the vessel to a uniform $190^{\circ} \mathrm{C}$ without any inductive heating. Since there is no personnel hazard from high voltage during non-inductive baking, this capability may be useful for specific conditioning purposes while maintaining access to the tokamak for maintenance.

Model 3 used data developed from baking at off normal conditions of inductive power and air inlet temperatures to predict the expected port temperature for the expected baking conditions. Planned improvements were expected to increase air inlet temperature to the vessel and port fluid circuits from $250^{\circ} \mathrm{C}$ to $330^{\circ} \mathrm{C}$ while inductive power would be decreased from the traditional steady-state value of $96 \%$ to about $70 \%$.

These port temperature projections, although nice in theory, were inaccurate in practice.

The general problem in projections from Models 2 and 3 is attributed to the difficulty in obtaining truly steady-state data at off normal operating points. In hindsight, the attempts to fully stabilize temperatures at three different operating points during a $16 \mathrm{hr}$ bake was not successful. Vessel temperatures stabilize within $2 \mathrm{hrs}$ but port flange temperatures take much longer. The port cooling circuits visible in Fig. 1 connect six ports in series. To obtain truely steady state port temperatures, all upstream ports must have attained steady state. In addition, measured port flange temperatures were between $210^{\circ} \mathrm{C}$ and $80^{\circ} \mathrm{C}$ which were related to their location relative to the inlet or outlet of the series of ports. The differences in type of ports, degree of insulation coverage, and equipment mounted in ports made predictions on port temperatures uncertain.

\section{IMPACT OF IMPROVED BAKING ON VESSEL CONDITIONING}

The most significant effect from the improved baking system is the more rapid increase in the vessel temperature. Since most of the outgassing from graphite tiles occurs above $300^{\circ} \mathrm{C}$, the increased time the can be spent above $300^{\circ} \mathrm{C}$ will result in significantly shorter times to outgas the graphite surfaces. This should permit more rapid recovery of good vacuum conditions following a vent of the system. In addition, the measured time at high temperature should permit significant outgassing of $\mathrm{D}_{2}$ and $\mathrm{He}$ in a short baking session following a day of plasma operation. This will permit much more effective leak checking to be performed on the morning following an operations day than we are presently able to perform. It will also permit a more rapid and complete changeover of fueling gas from one experimental day to another.

It is also expected that the increased temperature of some parts of the outer wall and the ports may improve vessel conditioning and reduce plasma impurity content. Some wall surfaces have been as cold as $230^{\circ} \mathrm{C}$ and some ports as cold as $70^{\circ} \mathrm{C}$. When neutral particles impact the contaminated surfaces of the metal ports, it may liberate low $\mathrm{Z}$ impurities $\left(\mathrm{CO}, \mathrm{H}_{2} \mathrm{O}, \mathrm{CH} 4\right)$ into the plasma. Initial outgassing rates obtained from the bake with the improved system indicated that as the temperature of the outer wall and ports exceeded those obtained in the past, the outgassing rate of $\mathrm{H}_{2} \mathrm{O}$ and the ratio of $\mathrm{H}_{2} \mathrm{O} / \mathrm{D}_{2} \mathrm{O}$ increased by a factor of approximately two. Typically, the two masses track each other and are both relatively steady or decrease slightly. The outgassing of $\mathrm{D}_{2} \mathrm{O}$ is likely primarily from the more porous plasma facing graphite tiles that absorb $\mathrm{D}_{2}$ during plasma operation. The increase in the $\mathrm{H}_{2} \mathrm{O}$ outgassing rate and the $\mathrm{H}_{2} \mathrm{O} / \mathrm{D}_{2} \mathrm{O}$ ratio indicates that despite over $100 \mathrm{hrs}$ of high temperature baking performed during 1999, the colder and possible less porous metal surfaces of the ports were never fully outgassed following their earlier exposure to air.

\section{SUMMARY}

Improvements made to the DIII-D baking system provide: 1) A quick ramp up to $350^{\circ} \mathrm{C}$ average vessel temperature reduced time required to reach steady-state from $14 \mathrm{hrs}$ to $4.5 \mathrm{hrs}$. 2) Improved temperature uniformity by significantly increasing the temperature of previously cooler areas of the tokamak i.e. the divertor rings, lower outer wall and ports. 3) The new $72 \mathrm{~kW}$ air heater should allow noninductive baking to about $190^{\circ} \mathrm{C}$ average to allow more flexibility in the vessel conditioning schedule.

Other observations are: 1) The inherent complexity present in the DIII-D baking system makes it difficult to predict the effect of system changes to high accuracy. 2) Hot gas baking of a double walled vessel can produce quite uniform temperatures (within $5^{\circ} \mathrm{C}$ ) throughout the vessel for the type of circuits used in DIII-D. 3) Inductive baking concentrates heating in the inner wall area of a tokamak. 4) Based on observation during baking, radiant heat transfer can be a significant factor for carbon tile surface temperatures above $300^{\circ} \mathrm{C}$. 5) The practice of connecting up to six ports in a series flow circuit with relatively low flow rate produces uneven temperatures for these ports during baking.

\section{REFERENCES}

[1] C.B. Baxi, et. al., "Design of Vacuum Vessel Heating System for DIII-D," Proc. 11th Symp. on Fusion Engineering, Austin Texas, Vol. 1, p. 952 (1985). 